Sun.

CLEA publishes also slides showing the retrograde motion of Mars in the Pleiades from which both the apparent motion and the variation of apparent magnitude of Mars can be determined using the Hyades and Pleiades stars as references.

The solar time at which a given apparent position of stars can be observed results from the two different motions of the Earth: its diurnal rotation and its annual revolution. The combination of these 2 motions can be illustrated by constructing either an astrolabe (ICE and CLEA) or a starfinder.

2.2 Analysis of light. In French senior high schools, a device initiated here in Holland by Minnaert is now widely used for measuring the solar constant.

RMR (ICE) published slides of variable stars (delta Cephei and Algol) from which students can determine very good light curves. Spectra of the Sun and stars are also widely used for illustrating either the Doppler effect or chemical composition. As an example, the spectrum of Beta Orionis, flanked by two emission spectra of argon, was taken by French school teachers using the $60 \mathrm{~cm}$ telescope at Pic du Midi, which is now open to amateurs. It is possible to ask the students to calibrate the spectrum, using the argon spectrum, from which they determine quickly the most intense features at $696.5 \mathrm{~nm}$ and around 420 . They are asked then to determine the wavelengths of 12 absorption lines and to identify them from a table.

\title{
CURRICULUM, ACTIVITIES AND RESOURCES: THE NORTH AMERICAN SYSTEM
}

\author{
John R. Percy
}

Erindale Campus, University of Toronto, Mississauga, Ontario, Canada L5L 1C6

E-mail: percy@astro.utoronto.ca

Introduction. The difference between the European and North American systems of education has been eloquently described by Wentzel (1990); see also other papers in the proceedings of IAU Colloquium \#105, the triennial reports of Canada, Mexico and the US in IAU Commission 46's newsletter, and an ongoing series of short papers on astronomy education in Mercury, published by the Astronomical Society of the Pacific, dealing with astronomy education in general $(22, \# 2)$, planetarium education $(22, \# 5)$, an astronomy camp $(22, \# 6)$, gender issues $(23, \# 1)$, image processing (23, \#2), student misconceptions $(23, \# 3)$ and education at the HarvardSmithsonian Center for Astrophysics (23, \#4).

Current concerns in North America include: a decline in students' interest and ability in science, low prestige and rewards of teaching as a profession, and lack of science and math background among elementary school teachers (a universal concern!). These concerns must be viewed in the context of the deepening gulf 
between the affluent and the disadvantaged, and of the need to cut budgets in order to reduce (or eliminate) the federal and state deficits. There is also concern that science, especially physical science, is taught in a way which is unappealing to women (and to others who are not necessarily deeply committed to the subject).

On a more positive note: there is genuine public concern about science education. President Bush, in 1990, stated that "By the year 2000, US students must be first in the world in math and science achievement." The annual education budget of the National Science Foundation (NSF) has risen from essentially zero to over $\$ 600,000,000$ in little more than a decade, and other government and private sources of funding are available. These have led to many exciting projects and programs in all branches of science education, including astronomy. There are thousands of enthusiastic astronomy teachers in schools across North America. The best students are as good as ever, as recent International Math and Science Olympiads have shown. Astronomy continues to be popular with students, as well as with the general public.

I should point out that, in Canada, my own country, there are no government funds to support individual or institutional initiatives in science education. The amount of astronomy taught in schools ranges from "some" to "practically none". The situation in Mexico is no better, and the many contributions of scientists such as Julieta Fierro and her colleagues are extremely important. The rest of this paper will focus on astronomy education in the US.

Projects and Programs. There is no national science curriculum in the US, so it is important to identify how new projects and programs will fit into the curriculum. The first major NSF-supported project was STAR (Science Teaching through its Astronomical Roots): The STAR team carried out extensive studies (Sadler and Luzader 1990), which determined that there were about 2000 astronomy courses and about 10,000 astronomy units (mostly in earth science courses) across the US, many of them taught by teachers who considered themselves amateur astronomers. The STAR approach was to: (i) be aware of student misconceptions; (ii) base lessons and activities on what students do not know; (iii) teach students only what they are capable of learning; (iv) eliminate unnecessary terms, units, equations and information; (v) emphasize simple, hands-on low-tech equipment which students can keep; (vi) involve expert teachers in testing, evaluation and refinement of the material. The Project STAR textbook and teachers' manual are now available (from Kendall/Hunt Publishers), and the hands-on material can be ordered from Learning Technologies Inc., 59 Walden St., Cambridge MA 02140, USA. The Project STAR text is massive; it would be useful to have a "mini-STAR" unit for earth science courses.

Project STAR was based at the Harvard-Smithsonian Center for Astrophysics. The group there has now embarked on: ARIES (Astronomy Resources for Intercurricular Elementary Science); ESTEEM (Earth Science Teachers Exploring Exemplary materials); IMAGE (Investigative Materials about Global Environments); InSIGHT (Investigative Stimuli for Intuitive Growth using High Technology); MicroObservatory - a small automated inexpensive imaging telescope system; the Private Universe Project - a series of TV programs on misconceptions in science; Research Techniques for Undergraduate Faculty in Small Observatories; and SPICA (Support Program for Instructional Competency in Astronomy). The latter project has produced an excellent activity book, mostly for grade 6 to 12, also available from 
Kendall/Hunt Publishers. Another excellent activity and resource book (Project ASTRO Handbook) is to be published by the Astronomical Society of the Pacific, in 1995.

There are a wide variety of other projects and programs which are part of this "wave" of new developments:

- linking teachers and classes with professional and amateur astronomers

- providing astronomical images and data to classes, for instruction and research

- developing new lab activities, and high school and undergraduate research opportunities

- applying image processing in high school and undergraduate labs

- providing telescopes and instruments to small colleges

- developing computer networks to link schools, data sources, and scientists

- upgrading instructors' skills, especially through summer workshops

It should be possible for astronomy educators, in many countries, to duplicate some of these projects and programs, and/or make use of the materials in their own classes.

Involvement of professional astronomers. In 1990, a workshop on "An Education Initiative in Astronomy" (Brown 1990) brought 17 key people together, from major scientific and educational societies across the US. This initiative would be an excellent model to use elsewhere. Among other things, it creates an instant "task group" on astronomy education. This workshop identified opportunities, outlined objectives, suggested strategies, and made recommendations. Most of all, it created momentum which continues to increase. This momentum has been fuelled by NSF interest and support.

Many US professional scientific and educational societies have had ongoing astronomy education programs: awards, committees and working groups, public lectures, teachers' workshops, magazines and materials, and education sessions at their annual meetings. (Every scientific society should have an education component to its annual meeting!). Three organizations: the American Association for the Advancement of Sciences, the National Science Teachers' Association, and the US National Academy of Sciences, have embarked on major curriculum reform studies. Other societies have taken advantage of NSF funding to expand their education activities. Spurred by encouragement and funds from NSF and NASA, astronomers are becoming aware of how to link their science and education.

Future Needs and Directions. With such a multitude of new projects and programs, it is important for the developers to co-ordinate and co-operate, to share the results of their efforts, and to reduce overlap in present and future initiatives. It is also important to disseminate the results effectively. This can be done by creating a directory (electronic and hard copy) of resources (materials and people), and making it available to all possible users.

One of the most difficult tasks is to reach and help the elementary school teachers, either through pre-service or in-service workshops. Given their limited backgrounds in science, their many classroom responsibilities, and their meagre budgets, the material provided must be simple, inexpensive, and easy to implement. If teachers can be enabled to teach a few topics well, their students would probably 
have more knowledge and more interest in the end. Many curriculum projects and programs are readily absorbed by the best teachers and students. The real challenge is to reach all teachers and all students, not just science specialists.

In an effort to address these needs, the Astronomical Society of the Pacific is organizing a major symposium on North American astronomy education in June 1995. The proceedings of this symposium are to be published in the ASP Conference Series sometime in 1996.

Brown, R.A. 1990. "An Education Initiative in Astronomy", Space Telescope Science Institute.

Sadler, P.M. and Luzader, W.M. 1990. In The Teaching of Astronomy, ed. Pasachoff and Percy, Cambridge UP.

Wentzel, D.G. 1990. In The Teaching of Astronomy, ed. Pasachoff and Percy, Cambridge UP.

\section{NEW TRENDS IN SCIENCE MUSEUMS}

Julieta Fierro

Instituto de Astronomia, UNAM, Apartado Postal 70-264, C.P. 04510 D.F., Mexico

E-mail: julieta@astroscu.unam.mx

\section{INTRODUCTION}

An effective way to teach astronomy in an informal manner is by way of popularization. Since the general public is heterogeneous, one must use as many resources as possible to reach a large amount of people. The common ways of popularization are: public lectures, planetarium shows, books, articles, television and radio programs, telescope viewing and one that might encompass all the rest if enough resources are available: a large astronomy hall in a museum or a science center.

Each way of popularization has its advantages. Public lectures give a chance to be in contact with the speaker, to ask questions and understand certain complex problems. Planetaria can give lots of shows and cover the basic educational needs of small communities. Unfortunately, not all developing countries own enough planetaria.

Publications, if well distributed, can reach a large number of people, can be saved, reread, etc. Not all developing countries have regular astronomy articles available to the general population nor astronomy books in native tongues. Libraries and bookstores are scarce; for instance, in Mexico there are a total of 300 bookstores for a population of 82 million people.

Mass media are of course an excellent way to reach a large public. In many developing countries there are no spaces dedicated to science in newspapers, radio and television programs; it is not considered part of culture.

Halls dedicated to astronomy can encompass part of the previous tools plus have 